\title{
Emerging Roles of the Endolumenal Functional Lumen Imaging Probe in Gastrointestinal Motility Disorders
}

\author{
Rona M Ata-Lawenko ${ }^{1}$ and Yeong Yeh Lee ${ }^{2 *}$ \\ ${ }^{1}$ Section of Gastroenterology, De La Salle Health Sciences Institute, Dasmarinas City, Cavite, Philippines; and ${ }^{2}$ School of Medical Sciences, \\ Universiti Sains Malaysia, Kubang Kerian, Kota Bahru, Kelantan, Malaysia
}

Gastrointestinal sphincters play a vital role in gut function and motility by separating the gut into functional segments. Traditionally, function of sphincters including the esophagogastric junction is studied using endoscopy and manometry. However, due to its dynamic biomechanical properties, data on distensibility and compliance may provide a more accurate representation of the sphincter function. The endolumenal functional lumen imaging probe (EndoFLIP) system uses a multi-detector impedance planimetry system to provide data on tissue distensibility and geometric changes in the sphincter as measured through resistance to volumetric distention with real-time images. With the advent of EndoFLIP studies, esophagogastric junction dysfunction and other disorders of the stomach and bowels may be better evaluated. It may be utilized as a tool in predicting effectiveness of endoscopic and surgical treatments as well as patient outcomes.

(J Neurogastroenterol Motil 2017;23:164-170)

Key Words

Compliance; Electric impedance; Esophagogastric junction; Humans; Manometry

\section{Introduction}

Gastrointestinal (GI) sphincters play a vital role in gut function and motility by separating the gut into functional segments. ${ }^{1}$ The esophagogastric junction (EGJ) is a dynamic mechanical structure separating the esophagus and stomach and it relies on extrinsic and intrinsic mechanisms to perform its function. ${ }^{1,2}$ Factors that contribute to effective trans-EGJ flow include peristalsis, gravity, the viscoelastic properties of the esophageal wall, and muscle tone of the crural diaphragm. ${ }^{3}$
High-resolution manometry is the current gold standard to determine the EGJ sphincter function. ${ }^{2}$ However, manometry measures static pressure exerted over an area of surrounding tissues and does not consider radial force. Additionally, manometry is also unable to differentiate between relaxed and contracted states of the EGJ. In the 1960s, Harris and Pope found that a contracting sphincter did not necessarily mean a competent EGJ. ${ }^{4}$ EGJ competence can be attributed to several other factors including tone, viscoelasticity, mechanoreception, and bolus transport. ${ }^{5}$ The measurement of radial force through resistance to distention, ie, distensibility, rather than pressure alone, should be a prime determinant

Received: October 13, 2016 Revised: None Accepted: November 20, 2016

(c) This is an Open Access article distributed under the terms of the Creative Commons Attribution Non-Commercial License (http://creativecommons. org/licenses/by-nc/4.0) which permits unrestricted non-commercial use, distribution, and reproduction in any medium, provided the original work is properly cited.

*Correspondence: Yeong Yeh Lee, MD, PhD, FACP, FRCP, FACG

School of Medical Sciences, Universiti Sains Malaysia, 16150 Kubang Kerian, Kelantan, Malaysia

Tel: +60-179028147, Fax: +60-97673949, E-mail: justnleeyy@gmail.com 
of sphincteric strength. ${ }^{6}$ The barostat, impedance planimetry (IP) and more recently, the functional lumen imaging probe (FLIP) are available techniques for measuring luminal distensibility. ${ }^{\top}$

The barostat measures the pressure and volume in tubular segments in a direct fashion, but the muscle tone indirectly. ${ }^{8,9}$ The principle of the barostat is to exert a constant pressure within a balloon to check for distensibility and to demonstrate pain thresholds. ${ }^{6,7}$

On the other hand, IP is a technique designed to measure the relationship of cross-sectional area (CSA) and pressure during constant volume distention in the GI lumen., ${ }^{3,9}$ Electrical impedance is converted into an area measurement. ${ }^{10}$ The CSA is used to estimate wall tension and strain inside the lumen. ${ }^{7}$ Originally developed for the study of the EGJ, Rao et al first described the IP technique as a method to quantify esophageal wall distensibility. ${ }^{9}$ By applying the law of Laplace, the wall tension can be calculated from CSA and pressure data. ${ }^{5}$ Through IP, the viscoelastic properties of the esophagus, which include circumferential wall tension, compliance, strain and wall stiffness, can be calculated. ${ }^{9}$ The threshold pressure for sensation can also be ascertained. The esophageal wall is compliant to stretch of up to a balloon distention of $40 \mathrm{~cm} \mathrm{H}_{2} 0 .{ }^{9}$ The CSApressure relationship at a constant volume is referred as the wall distensibility. ${ }^{11}$

The newer FLIP adopts the same principle of IP. ${ }^{10,12,13}$ The endolumenal FLIP (EndoFLIP) EF-100 System (Crospon Ltd, Galway, Ireland) uses a multi-detector IP system to produce a 3-di- mensional outline of a distensible organ (Fig. 1A). ${ }^{7,10}$ The concept of FLIP was first demonstrated by McMahon and Gregersen in 2007. ${ }^{1}$ Tissue distensibility and geometric changes in the EGJ are measured through resistance to volumetric distention with real-time images. ${ }^{2,6,14,15}$ EGJ distensibility index is calculated as the narrowest CSA divided by balloon distending pressure. In healthy volunteers, Lin et al established a linear EGJ CSA-pressure relationship using a balloon distending pressure below $8 \mathrm{mmHg}$ and there was regional distensibility differences with the greatest distensibility seen $3 \mathrm{~cm}$ above the EGJ.

\section{Test Equipment}

The EndoFLIP EF-325N measurement probe consists of a polyutherane balloon mounted on the distal $14 \mathrm{~cm}$ of a plastic catheter which is $240 \mathrm{~cm}$ long, and $3 \mathrm{~mm}$ wide (Fig. 1B) ${ }^{15,16}$ The balloon assumes a cylindrical shape providing an image that is 8 $\mathrm{cm}$ long, with a diameter of $2.5 \mathrm{~cm}$, and a maximal $50 \mathrm{~mL}$ capacity. ${ }^{13,16}$ Within the balloon, there is a $16 \mathrm{~cm}$ IP segment with 17 ring electrodes spaced $5 \mathrm{~mm}$ apart and also a solid state pressure transducer. ${ }^{3,14,15}$ When inflated, the balloon may be distended to a maximal diameter of $2.5 \mathrm{~cm}$ and a CSA of $490 \mathrm{~mm}^{2}$. . The balloon can be filled with a specially formulated saline solution. ${ }^{13}$ The EndoFLIP EF-100 system is pre-calibrated but catheters require a pre-use purge sequence to remove air from the inflation line and
A

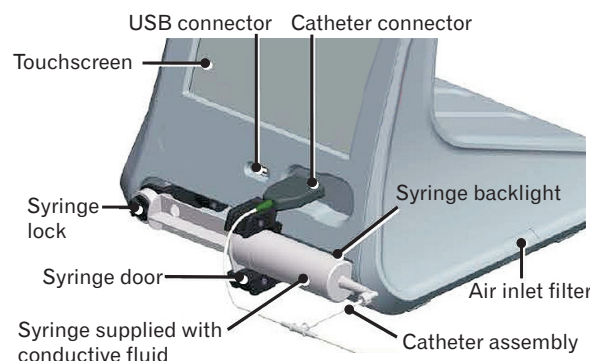

B

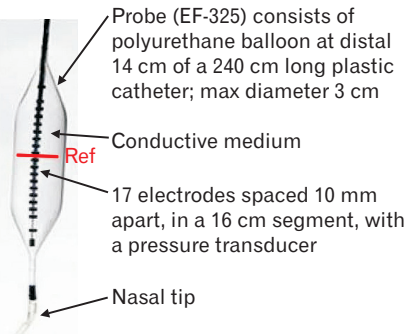

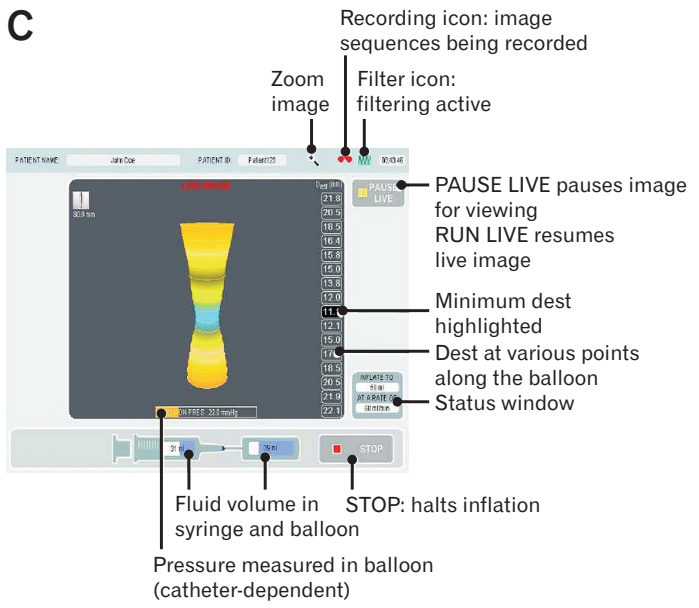

Figure 1. Components of the endolumenal functional lumen imaging probe (EndoFLIP; EF100) system. (A) There is a catheter connector that connects the syringe which is held by a syringe door and lock to the catheter. There are several catheters but the most common is EF-325 (for description, see B). The recording unit has a touchscreen display with a primary user interface (for description, see C). (B) The catheter (EF-325N) is a $240 \mathrm{~cm}$ long plastic catheter with a polyurethrane balloon at its distal end with a maximum diameter of $2.5 \mathrm{~cm}$. Conductive medium fills the balloon during inflation, and within the balloon there are 17 impedance electrodes within a $8 \mathrm{~cm}$ segment. Ref is midpoint of the balloon catheter. (C) The display has a friendly touchscreen interface that includes injection volume controls, live images of the balloon inflation and a status window. 
balloon (Fig. 1A). ${ }^{13}$ The catheter's protective sheath is removed and the balloon is placed inside the pre-use metallic tube. ${ }^{15}$ Once turned on, the system monitor has a touchscreen control function (Fig. 1C). Both the catheter probe and syringe are connected to the unit to begin the automated purge sequence. ${ }^{5}$

\section{Test Procedure}

The distal end of probe is lubricated with gel if inserted nasally or it can be inserted alongside the endoscope channel until the balloon is oriented in the esophagus. ${ }^{15}$ For upper GI evaluation, the study subject is required to fast for at least 6 hours. ${ }^{12}$ Topical anesthesia is administered to the posterior pharyngeal wall and the subject is then instructed to lie supine with the head tilted by approximately $30^{\circ}$ for catheter insertion. ${ }^{5}$ The catheter may be inserted trans-orally until the $45 \mathrm{~cm}$ mark is at the level of the patient's teeth or trans-nasally until the $55 \mathrm{~cm}$ mark is at the level of the patient's nares for EGJ studies. ${ }^{2}$ The catheters are inserted alongside the endoscope and positioned at the EGJ under direct vision. ${ }^{13}$ Once the probe is placed straddling the EGJ, the balloon is inflated typically to $30 \mathrm{~mL}$ or $40 \mathrm{~mL}$. $^{13}$ The monitor will display the EGJ shape which can then be saved for later analysis. Subjects are asked to avoid swallowing during balloon inflation. ${ }^{15}$ Measurement of CSA and pressure can be performed up to a maximum volume of $50 \mathrm{~mL}$. Once the procedure is completed, the balloon is deflated fully and may be removed. The catheter can also be used to evaluate other sphincters such as the pyloric sphincter and anal sphincter, and similar procedural steps can be applied to these sphincters.

\section{Analysis of Endolumenal Functional Lumen Imaging Probe Data}

The balloon distention volume, intra-balloon pressure, and planimetry data are displayed in real-time. ${ }^{3,12}$ The system generates FLIP images at a sampling rate of $10 \mathrm{~Hz}^{2,3}$ The bag assumes an hourglass shape with the central constriction at the least distensible locus. ${ }^{12}$ Some researchers calculate the median of each CSA and intra-balloon pressure for 30 seconds at each volume distention. ${ }^{16}$ The distensibility index $\left(\mathrm{mm}^{2} / \mathrm{mmHg}\right)$ is displayed on the unit. Compliance $\left(\mathrm{mm}^{3} / \mathrm{mmHg}\right)$ is also displayed, it being the volume between $1 \mathrm{~cm}$ above and $1 \mathrm{~cm}$ below the narrowest point in the EGJ divided by intra-balloon pressure. Wall tension $(\mathrm{mmHg} \cdot \mathrm{mm})$ can be calculated according to the Laplace's law, ie, tension $=$ distention pressure $\times$ measured minimum radius. ${ }^{14}$

\section{Clinical Utility}

The indications for clinical use in GI motility disorders of EndoFLIP are expanding. Besides providing physiological data, this technique can guide subsequent clinical management based

Table. The Rationale and Call to Action Using Functional Lumen Imaging Probe Parameters in Upper Gastrointestinal Conditions

\begin{tabular}{|c|c|c|}
\hline Conditions & Rationale & Call to action \\
\hline Achalasia & $\begin{array}{l}\text { Provides the equivalence of barium height test but } \\
\text { during endoscopy. }\end{array}$ & $\begin{array}{l}\text { Distensibility } \leq 1 \mathrm{~mm}^{2} / \mathrm{mmHg} \text { and diameter } \leq 5 \mathrm{~mm} \\
\text { may indicate the need for dilatation/POEM/Heller } \\
\text { myotomy. }\end{array}$ \\
\hline Eosinophilic esophagitis & $\begin{array}{l}\text { Narrow caliber esophagus is highly predictive of food } \\
\text { impaction. }\end{array}$ & $\begin{array}{l}\text { Focal diameter } \leq 17 \mathrm{~mm} \text { indicates the need for dilata- } \\
\text { tion or drug intervention. }\end{array}$ \\
\hline Stricture & $\begin{array}{l}\text { Determine stricture size and gauge if dilation is need- } \\
\text { ed. }\end{array}$ & If diameter $\leq 17 \mathrm{~mm}$ indicates the need for dilatation. \\
\hline Gastroesophageal reflux disease & $\begin{array}{l}\text { Useful adjunct to Hill grading of the gastroesophageal } \\
\text { flap valve geometry during endoscopy. }\end{array}$ & $\begin{array}{l}\text { Diameter }>9-10 \mathrm{~mm} \text { suggests that fundoplication may } \\
\text { be beneficial. } \\
\text { May help to select optimal patients for minimally inva- } \\
\text { sive procedures. }\end{array}$ \\
\hline Gastroparesis & $\begin{array}{l}\text { Helps to select pylorus problem from antral problem } \\
\text { by measuring pylorus stiffness or laxity. More than } \\
\text { half of patients may not derive benefit from treatment } \\
\text { of pylorus because of incorrect patient selection, and } \\
\text { EndoFLIP can help to select the right patients who } \\
\text { may benefit from botox/dilatation. }\end{array}$ & $\begin{array}{l}\text { Distensibility }<10 \mathrm{~mm}^{2} / \mathrm{mmHg} \text { suggests the pylorus } \\
\text { will benefit from treatment }\end{array}$ \\
\hline
\end{tabular}

POEM, peroral endoscopic myotomy; EndoFLIP, endolumenal functional lumen imaging probe. 


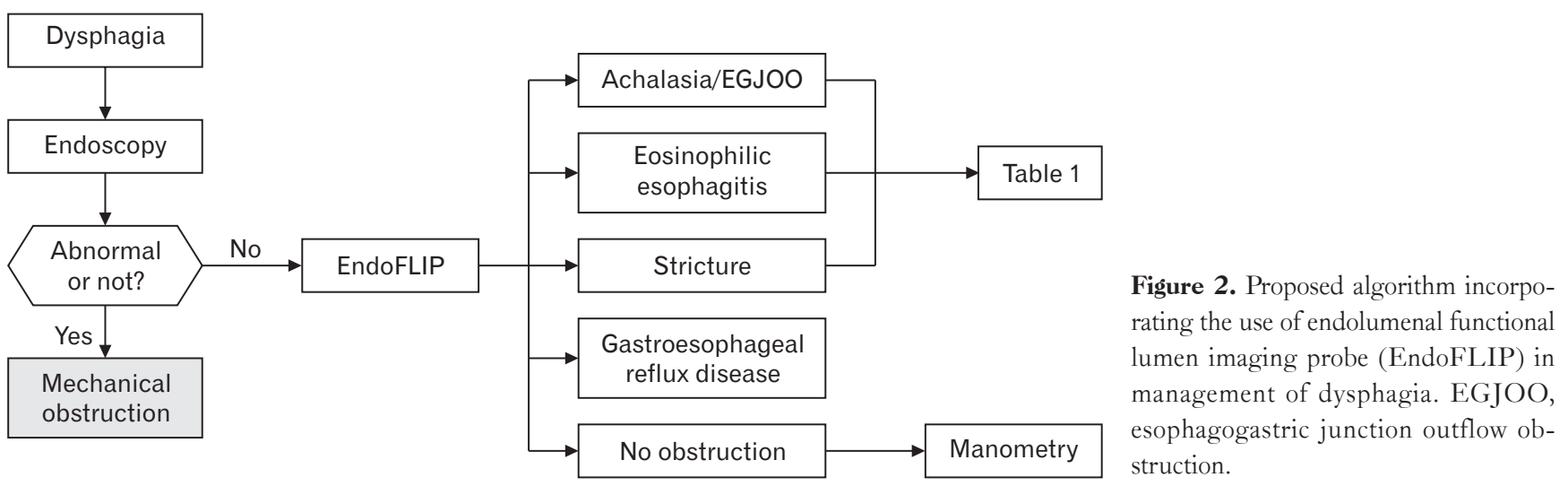

on distensibility or diameter cut-offs (Table). Being a common problem, dysphagia is an obvious indication for EndoFLIP that can be performed at the time of endoscopy (Fig. 2). Findings from EndoFLIP can determine if further manometry studies or subsequent therapy are needed, for instance in cases of narrow esophagus lumen or of EGJ outflow obstruction.

\section{Achalasia}

In contrast to lower esophageal sphincter (LES) measurement by manometry, EGJ distensibility in achalasia better predicts esophageal emptying and clinical response to therapies. ${ }^{17}$ Pandolfino et $\mathrm{al}^{18}$ showed that EGJ distensibility was significantly greater in a successfully treated achalasia group than an untreated achalasia group. There was also a significant correlation between the Eckardt symptom score severity and EGJ distensibility. ${ }^{18}$ EndoFLIP also detects esophageal contractility that is not observed with manometry in achalasia ${ }^{19}$ and may in future be useful in subtyping of achalasia. ${ }^{20}$ We propose that a distensibility of $\leq 1 \mathrm{~mm}^{2} / \mathrm{mmHg}$ and a diameter $\leq 5 \mathrm{~mm}$ as cut-offs for the need of dilation or peroral endoscopic myotomy (POEM) or myotomy (Table). Distensibility of the EGJ was found to increase following pneumatic dilation ${ }^{20}$ but a successful outcome may require that the dilation achieves a higher distensibility than that found in normal subjects due to incompetent motility in this group of patients. ${ }^{21,22}$ Familiari et al ${ }^{23}$ studied the utility of EndoFLIP in patients who underwent POEM for achalasia and found a substantial post-POEM increases in the diameter and CSA of the EGJ. Subsequent studies of EndoFLIP in POEM and Heller's myotomy have proven the usefulness of distensibility measurement. ${ }^{24,25}$

\section{Eosinophilic Esophagitis}

Reduced esophageal distensibility in eosinophilic esophagitis
(EoE) was significantly associated with increased risk of symptoms and increased likelihood of eventual need for dilation. ${ }^{26,27} \mathrm{~A}$ focal diameter $\leq 17 \mathrm{~mm}$ indicates the need for dilation or drug intervention in $\mathrm{EoE}$ (Table). The same criteria can be applied for esophageal stricture. FLIP topography is a new FLIP technique in development that describes regional variation of CSA over time, and it can provide a more global assessment of distensibility along the axial plane and allows differentiation of endoscopic phenotypes. ${ }^{28} \mathrm{~A}$ more recent study suggests that endoscopic ring severity may serve as a marker of remodelling with lower distensibility in higher ring scores. ${ }^{29}$ Eosinophil counts have poor correlation both with posttreatment symptoms, and with distensibility, whereas the distensibility plateau has been shown to correlate with symptoms. ${ }^{27,29}$

\section{Gastroesophageal Reflux Disease and Anti-reflux Surgery}

In gastroesophageal reflux disease (GERD), a primary abnormality is an increased reflux volume from an abnormally compliant or more distensible EGJ. ${ }^{30}$ The Hill grade is used to assess the gastroesophageal flap valve geometry, ${ }^{31}$ and EndoFLIP can be an useful adjunct. Kwiatek and colleagues showed an increase in EGJ distensibility of up to 3-fold in GERD patients compared to controls. ${ }^{13}$ In addition, McMahon et al ${ }^{6}$ observed that GERD patients had more distensible and shorter length hiatus than normal subjects. Likewise, Lottrup et $\mathrm{al}^{8}$ has shown increases in distensibility in patients with hiatal hernia. EndoFLIP may also be used to assess GEJ distensibility prior to antireflux surgery for surgical technique planning and for assessing long-term outcomes. We propose that a diameter $>9-10 \mathrm{~mm}$ in patients with GERD indicates that Nissen fundoplication may be beneficial (Table). Kwiatek et $\mathrm{al}^{12}$ compared EGJ compliance in patients who underwent fundoplication using FLIP. Their findings showed that the least distensible locus was at 
the hiatus and that compared to controls, fundoplication patients had significantly lower EGJ distensibility and EGJ compliance. Furthermore, the FLIP study demonstrated both an increased length of the constricted segment after fundoplication and reduced compliance.

\section{Upper Esophageal Sphincter Evaluation}

Besides the EGJ, FLIP has been utilized in the study of the upper esophageal sphincter (UES). Regan et al studied its utility in the measurement of UES distensibility among healthy volunteers. ${ }^{15}$ The authors have successfully measured the UES diameter and pressure at rest, during swallowing and voluntary maneuvers. Further study by the same group allowed measurement of UES distensibility and opening patterns during swallowing. ${ }^{32}$ Further research is needed to establish clinical utility in UES related disorders.

\section{Gastroparesis}

EndoFLIP has been shown to be a feasible technique in the measurement of pyloric distensibility, and in a study, early satiety and postprandial fullness were found to be inversely correlated with diameter and CSA of the pylorus. ${ }^{33}$ In addition, fasting pyloric compliance was found to decrease in a sub-group of gastroparetic patients, and dilation in these patients improved the quality of life scores. ${ }^{34}$ The basal pyloric pressure was also found to be elevated in almost half of patients with nausea and vomiting and delayed gastric emptying. ${ }^{35}$ The above findings suggest that EndoFLIP can help to identify the appropriate pylorus that may benefit from intervention. Botox and dilation interventions only provide benefit in less than half of gastroparetic patients and the reason may be incorrect selection of patients. We propose a distensibility $<10 \mathrm{~mm}^{2} / \mathrm{mmHg}$ as the cut-off criteria for pyloric intervention (Table).

\section{Sphincter of Oddi Evaluation}

By using a smaller probe, Kunwald et $\mathrm{al}^{36}$ were able to demonstrate the feasibility and reproducibility of FLIP technique in sphincter of Oddi function studies. Its potential role in the management of sphincter of Oddi dysfunction, however, needs further investigation.

\section{Anal Sphincter Evaluation and Fecal Incontinence}

Due to segmental dynamic properties of the anal muscles, manometry alone may be insufficient to determine the biomechanical properties of the anal canal. Luft et al, ${ }^{14}$ studied the use of EndoFLIP in assessing anal canal properties in healthy individuals. The authors concluded that the upper part of the anal canal is the most compliant and that the least distensible part is the mid-anal canal region, which contributes the most to resting anal continence. ${ }^{14}$ Similar results were reported by Alqudah et al. ${ }^{37}$ In a study by Gourcerol et $\mathrm{al}^{38}$ comparing the use of EndoFLIP and 3-dimensional high-resolution manometry, it was found that anal distensibility index was higher at rest and during voluntary contraction in fecal incontinence than in healthy subjects, and that the discrimination was better using the distensibility index as compared with the anal pressure. EndoFLIP may be used intra-operatively to assess the anal sphincter geometry and tightness during repair or augmentation. The anal canal length, anal canal diameter derived from the EndoFLIP study and rectal pressure from manometry can be used to calculate the flow which allows identification of incontinence phenotyping. Further studies are needed to confirm the above findings.

\section{Safety and Future Development}

The procedure is well-tolerated and there have been no adverse events reported thus far. Despite being so, there must be caution for potential perforation in post-operative and post-radiation conditions, and especially when the insertion is blind without endoscopic guidance.

As mentioned above, FLIP topography is a new technique and future development of the system may incorporate this new method. EndoFLIP has only been in clinical use since 2009, but despite being a relatively young technology, there has been tremendous interest in the technology within the scientific and medical community. Other developments may include the use of EndoFLIP in a management algorithm such as shown in Figure 2 to guide the use of further investigation or interventions.

\section{Conclusion}

The EndoFLIP provides data on the biomechanical properties of GI sphincters and walls. The measurement of EGJ distensibility and compliance has been shown to be useful in disorders such as GERD, EoE, and achalasia. It may also be used as a tool in predicting effectiveness of endoscopic and surgical treatments as well as patient outcomes. With FLIP, other sphincters in the GI tract including the anal canal may also be studied.

Acknowledgements: We also thanked Crospon Ltd and MedicPro Supplies Sdn Bhd for providing the necessary information and support towards the current work. 
Financial support: Part of research in the current paper was funded by the Research University Individual (RUI) grant of Universiti Sains Malaysia (Grant No. 1001/PPSP/812151).

\section{Conflicts of interest: None.}

Author contributions: Yeong Yeh Lee and Rona M AtaLawenko contributed equally to conception, methods, literature reviews, and writing of manuscript.

\section{References}

1. McMahon BP, Drewes AM, Gregersen H. Functional oesophagogastric junction imaging. World J Gastroenterol 2006;12:2818-2824.

2. McMahon BP, Frøkjaer JB, Kunwald P, et al. The functional lumen imaging probe (FLIP) for evaluation of the esophagogastric junction. Am J Physiol Gastrointest Liver Physiol 2007;292:G377-G384.

3. Lin Z, Nicodème F, Boris L, et al. Regional variation in distal esophagus distensibility assessed using the functional luminal imaging probe (FLIP). Neurogastroenterol Motil 2013;25:e765-e771.

4. Harris LD, Pope CE 2nd. "Squeeze" vs. resistance: an evaluation of the mechanism of sphincter competence. J Clin Invest 1964;43:2272-2278.

5. McMahon BP, Frøkjaer JB, Drewes AM, et al. A new measurement of oesophago-gastric junction competence. Neurogastroenterol Motil 2004;16:543-546.

6. McMahon BP, Jobe BA, Pandolfino JE, Gregersen H. Do we really understand the role of the oesophagogastric junction in disease? World $\mathrm{J}$ Gastroenterol 2009;15:144-150.

7. Gregersen H, Drewes AM, McMahon BP, Liao D. Balloon-distension studies in the gastrointestinal tract: current role. Dig Dis 2006;24:286296.

8. Lottrup C, Gregersen H, Liao D, et al. Functional lumen imaging of the gastrointestinal tract. J Gastroenterol 2015;50:1005-1016.

9. Rao SS, Hayek B, Summers RW. Impedance planimetry: an integrated approach for assessing sensory, active, and passive biomechanical properties of the human esophagus. Am J Gastroenterol 1995;90:431-438.

10. Hoppo T, McMahon BP, Witteman BPL. Functional lumen imaging probe to assess geometric changes in the esophagogastric junction following endolumenal fundoplication. J Gastrointest Surg 2011;15:11121120.

11. Pandolfino JE, Shi G, Curry J, Joehl RJ, Brasseur JG, Kahrilas PJ. Esophagogastric junction distensibility: a factor contributing to sphincter incompetence. Am J Physiol Gastrointest Liver Physiol 2002;282: G1052-G1058.

12. Kwiatek MA, Kahrilas K, Soper NJ, et al. Esophagogastric junction distensibility after fundoplication assessed with a novel functional luminal imaging probe. J Gastrointest Surg 2010;14:268-276.

13. Kwiatek MA, Pandolfino JE, Hirano I, Kahrilas PJ. Esophagogastric junction distensibility assessed with an endoscopic functional luminal imaging probe (EndoFLIP). Gastrointest Endosc 2010;72:272-278.

14. Luft F, Fynne L, Gregersen H, et al. Functional luminal imaging probe: a new technique for dynamic evaluation of mechanical properties of the anal canal. Tech Coloproctol 2012;16:451-457.

15. Regan J, Walshe M, Rommel N, McMahon BP. A new evaluation of the upper esophageal sphincter using the functional lumen imaging probe: a preliminary report. Dis Esophagus 26:117-123.

16. Tucker E, Sweis R, Anggiansah A, et al. Measurement of esophagogastric junction cross-sectional area and distensibility by an endolumenal functional lumen imaging probe for the diagnosis of gastroesophageal reflux disease. Neurogastroenterol Motil 2013;25:904-910.

17. Rohof WO, Hirsch DP, Kessing BF, Boeckxstaens GE. Efficacy of treatment for patients with achalasia depends on the distensibility of the esophagogastric junction. Gastroenterology 2012;143:328-335.

18. Pandolfino JE, de Ruigh A, Nicodème F, Xiao Y, Boris L, Kahrilas PJ. Distensibility of the esophagogastric junction assessed with the functional lumen imaging probe $\left(\right.$ FLIP $\left.^{\mathrm{TM}}\right)$ in achalasia patients. Neurogastroenterol Motil 2013;25:496-501.

19. Ponds FA, Bredenoord AJ, Kessing BF, Smout AJ. Esophagogastric junction distensibility identifies achalasia subgroup with manometrically normal esophagogastric junction relaxation. Neurogastroenterol Motil 2017;29:e12908.

20. Smeets FG, Masclee AA, Keszthelyi D, Tjwa ET, Conchillo JM. Esophagogastric junction distensibility in the management of achalasia patients: relation to treatment outcome. Neurogastroenterol Motil 2015;27:1495-1503

21. O'Dea J. Dilation in Achalasia - is normal distensibility enough? Neurogastroenterol Motil 2016;28:153.

22. Smeets FG, Masclee AA, Keszthelyi D, Tjwa ET, Conchillo JM. Dilation in achalasia - is normal distensibility enough: Author's reply. Neurogastroenterol Motil 2016;28:154-155.

23. Familiari P, Gigante G, Marchese M, et al. EndoFLIP system for the intraoperative evaluation of peroral endoscopic myotomy. United European Gastroenterol J 2014;2:77-83.

24. Ilczyszyn A, Hamaoui K, Cartwright J, Botha A. Intraoperative distensibility measurement during laparoscopic Heller's myotomy for achalasia may reduce the myotomy length without compromising patient outcome. Dis Esophagus 2016;29:455-462.

25. Ngamruengphong S, von Rahden $\mathrm{BH}$, Filser J, et al. Intraoperative measurement of esophagogastric junction cross-sectional area by impedance planimetry correlates with clinical outcomes of peroral endoscopic myotomy for achalasia: a multicenter study. Surg Endosc 2016;30:28862894.

26. Nicodème F, Hirano I, Chen J, et al. Esophageal distensibility as a measure of disease severity in patients with eosinophilic esophagitis. Clin Gastroenterol Hepatol 2013;11:1101-1107.e1.

27. Kwiatek MA, Hirano I, Kahrilas PJ, Rothe J, Luger D, Pandofino JE. Mechanical properties of the esophagus in eosinophilic esophagitis. Gastroenterology 2011;140:82-90.

28. Lin Z, Kahrilas PJ, Xiao Y, et al. Functional luminal imaging probe topography: an improved method for characterizing esophageal distensibility in eosinophilic esophagitis. Therap Adv Gastroenterol 2013;6:97-107.

29. Chen JW, Pandolfino JE, Lin Z, et al. Severity of endoscopically identified esophageal rings correlates with reduced esophageal distensibility in 
eosinophilic esophagitis. Endoscopy 2016;48:794-801.

30. Pandolfino JE, Shi G, Curry J, Joehl RJ, Brasseur JG, Kahrilas PJ. Esophagogastric junction distensibility: a factor contributing to sphincter incompetence. Am J Physiol Gastrointest Liver Physiol 2002;282:G1052-G1058.

31. Hill LD, Kozarek RA. The gastroesophageal flap valve. J Clin Gastroenterol 1999;28:194-197.

32. Regan J, Walshe M, Rommel N, Tack J, McMahon BP. New measures of upper esophageal sphincter distensibility and opening patterns during swallowing in healthy subjects using EndoFLIP®. Neurogastroenterol Motil 2013;25:e25-e34.

33. Malik Z, Sankineni A, Parkman HP. Assessing pyloric sphincter pathophysiology using EndoFLIP in patients with gastroparesis. Neurogastroenterol Motil 2015;27:524-531.

34. Gourcerol G, Tissier F, Melchior C, et al. Impaired fasting pyloric com- pliance in gastroparesis and the therapeutic response to pyloric dilatation. Aliment Pharmacol Ther 2015;41:360-367.

35. Snape WJ, Lin MS, Agarwal N, Shaw RE. Evaluation of the pylorus with concurrent intraluminal pressure and EndoFLIP in patients with nausea and vomiting. Neurogastroenterol Motil 2016;28:758-764.

36. Kunwald P, Drewes AM, Kjaer D, et al. A new distensibility technique to measure sphincter of Oddi function. Neurogastroenterol Motil 2010;22:978-983, e253.

37. Alqudah MM, Gregersen H, Drewes AM, Mcmahon BP. Evaluation of anal sphincter resistance and distensibility in healthy controls using EndoFLIPC). Neurogastroenterol Motil 2012;24:e591-e599.

38. Gourcerol G, Granier S, Bridoux V, Menard JF, Ducrotté P, Leroi AM. Do endoflip assessments of anal sphincter distensibility provide more information on patients with fecal incontinence than high-resolution anal manometry? Neurogastroenterol Motil 2016;28:399-409. 